\title{
MATHEMATICAL ALGORITHM OF FUZZY LOGIC CONTROLLER FOR MULTILEVEL INVERTER CREATING VERTICAL DIVIDED VOLTAGE
}

\author{
EROL CAN \\ Department of Aircraft Airframe and Power plant, School of Civil Aviation, Erzincan University \\ correspondence: cn_e@hotmail.com
}

\begin{abstract}
A 9-level inverter with a boost converter has been controlled with a fuzzy logic controller and a PID controller for regulating output voltage applications on resistive $(R)$ and inductive $(L)$, capacitance $(C)$. The mathematical model of this system is created according to the fuzzy logic controlling new high multilevel inverter with a boost converter. The DC-DC boost converter and the multi-level inverter are designed and explained, when creating a mathematical model after a linear pulse width modulation (LPWM), it is preferred to operate the boost multi-level inverter. The fuzzy logic control and the PID control are used to manage the LPWM that allows the switches to operate. The fuzzy logic algorithm is presented by giving necessary mathematical equations that have second-degree differential equations for the fuzzy logic controller. After that, the fuzzy logic controller is set up in the 9-level inverter. The proposed model runs on different membership positions of the triangles at the fuzzy logic controller after testing the PID controller. After the output voltage of the converter, the output voltage of the inverter and the output current of the inverter are observed at the MATLAB SIMULINK, the obtained results are analysed and compared. The results show the demanded performance of the inverter and approve the contribution of the fuzzy logic control on multi-level inverter circuits.
\end{abstract}

KEYWORDs: differential equations; LPWM; fuzzy logic; PID.

\section{INTRODUCTION}

The DC-DC power converters are widely used in some applications, e.g., regulations of power supplies for personal computers, office equipment, aircraft power systems, and DC motor drives. Then, the regulated direct current (DC) sources have to convert to alternating current (AC) sources with an inverter. Multilevel inverter topologies provide an analytical designation for increasing the quality of the alternating voltage [1, 2]. Therefore, power electronic applications are important for converting a direct current source on the multilevel inverter. Some circuit studies were done in scientific articles [2, 3. However, the control signal techniques that are pulse-width modulations (PWMs) for the three-phase alternating machine and computer supply cause some difficulties [6. In addition, low-level inverters with a pulse-width modulation (PWM) can generate a waveform, which has harmonics because inverters have a nonlinear component such as MOSFET and IGBT [3 5]. If numbers of the component have increased on the inverter, non-linear effect such as harmonic distortion rises on the outputs of loads. The nonlinear effects have been addressed in some studies so that harmonic distortions could be eliminated on PWM inverters' running loads [8-10]. The fuzzy logic controller controlling a novel boost multi-level inverter topology is presented in the study, which is different from other studies [11, 12]. The proposed inverter topology uses a single $\mathrm{H}$-bridge structure creating DC voltage steps at loads according to increasing number of switches of the inverter. The output voltage of the DC-DC converter is boosted for an input voltage of the inverter. Therefore, the converter is designed for the input of the inverter. a nine-level inverter is designed with a high-level inverter method. According to the method, two switches are placed on the upper side of DC sources when a part of the DC source is added to the inverter with creating a voltage divider circuit. The switch quantity of the negative side of the source continues to be fixed by using logic gates, although the switch quantity of the positive side of the source is raised. After a boost nine-level inverter has been formed, the Linear Pulse Width Modulation is designed for an operation of the inverter in the signal processing study. The PWM inverter needs to operate on a closed-loop control so that optimal results could be obtained. Therefore, some control methods as a PID controller and Fuzzy logic controller has been used to control the power electronic circuits [9, 18. The inverters, which have a conventional hardware structure in previous studies, are controlled by SPWM, which provides the voltage steps on the load. The voltages are divided into horizontal pieces of different magnitudes on a load of a conventional inverter. Hence, the effect of the PWM control on the electrical angle of the current and voltage generated on the load cannot be determined precisely. For the first time, the proposed inverter structure with the LPWM is operated by the fuzzy logic control in a closed-loop and the generated voltage is composed of vertical pieces while each piece of the vertical axes has equal time. 


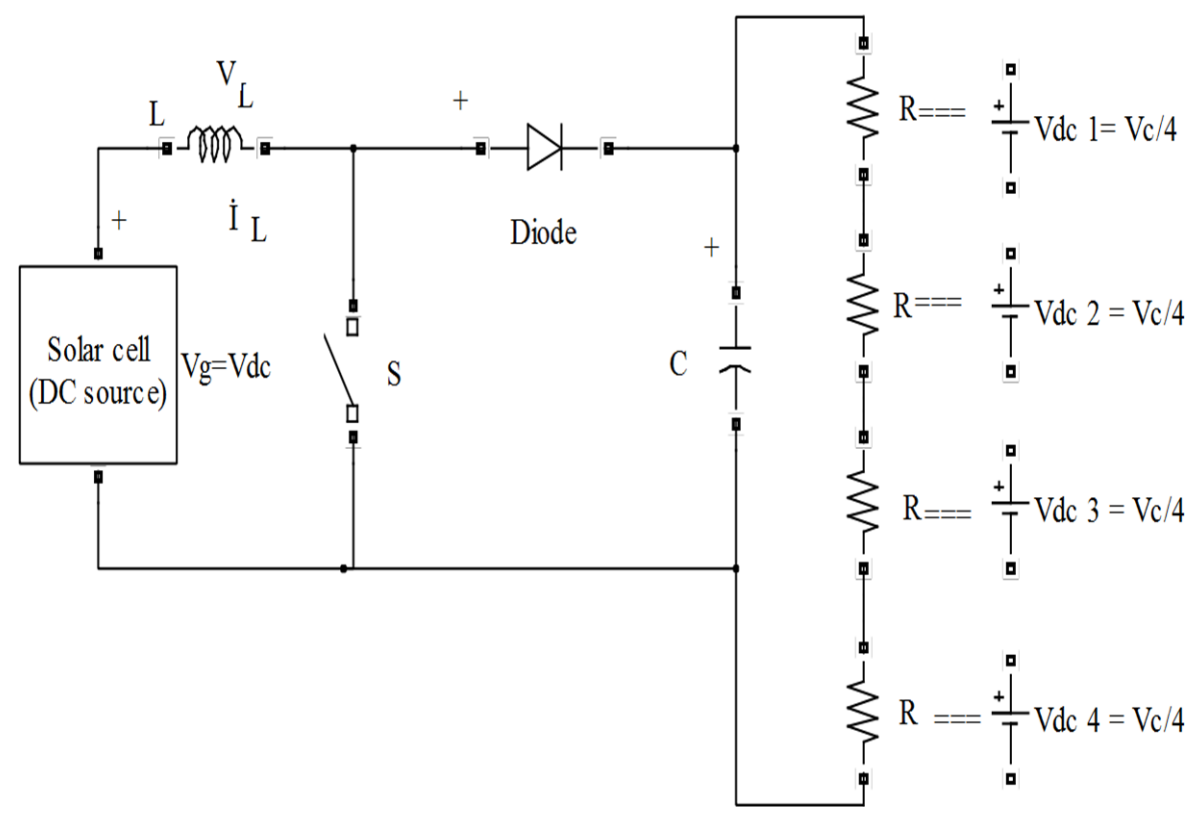

Figure 1. Boost converter with voltage divider.

This provides that the error and the change of error will be between the specified electrical angles while an inverter is being controlled. However, in the previous inverter control operation, the electrical angle could not be determined for the error and the error changes. According to this, the Fuzzy logic algorithm is presented by giving necessary mathematical equations for the fuzzy logic controller. Then, a boost high multi-level inverter that was present without the control system and without boost converter circuits at an open loop control [2, is designed with a PID and fuzzy logic controllers at the closed-loop control. Although the operation of the multilevel inverter is difficult on the closed-loop, the inverter achieves to perform with the fuzzy logic controller according to the proposed method. In the applications, the fuzzy logic controller is designed with three triangles according to the output current on the load. After load outputs of the fuzzy logic controlling inverter are tested on different positions of triangles, the obtained results are compared with the load outputs of the PID controlling inverter. According to the observed results, novel multilevel inverters provide high quality and stable output waveforms with a lower total harmonic distortion and a better harmonic spectrum than results of a traditional PID controlling inverter. Obtained harmonic distortions for the current are lower than $4 \%$, which is an international IEEE standard.

\section{Proposed INVERTER}

\subsection{DC-DC Boost CONVERTER}

Figure 1 shows a DC-DC boost converter for increasing the low-level DC voltage to a high-level DC voltage. The dc-dc converter circuit model is described by creating equations according to input and output values. In the equations, $\mathrm{Vg}$ is the input voltage, $\mathrm{VL}$ is the inductor voltage, and IL is the inductor current, R is the resistive load, $\mathrm{C}$ is the capacitor for the converter of the output voltage, $\mathrm{D}$ is the duty cycle for switches, $\mathrm{Vc}_{\mathrm{c}}$ is the output voltage that is divided by a voltage divider circuit for every level of the multilevel inverter and $\mathrm{T}$ is the total process time for the converter switch.

\subsection{LPWM AND INVERTER}

The pulse width modulation is used widely for driven motors and different driving loads [13 21. In this paper, the linear pulse width modulation (LPWM) is considered for switching the frequency strategy at the signal processing since the pulse width modulation is different from using a pulse width modulation method for multilevel inverters. One constant signal is compared to fourteen triangles for the 9-level inverter in Figure 2

Multilevel topologies are continuously considered for full bridge and half-bridge inverters, which were used, in a power electronic work [6]. The different pulse width modulation strategies experimented with the multi-level inverter so that the DC voltage is converted to an alternating voltage, which must include a low total harmonic distortion. Therefore, a different topology is offered in this study, although many studies have introduced variance to the available topologies [7. In the study, a boost high multi-level inverter is described with a fuzzy logic controller in closed loop control because the presented high multi-level inverter was introduced without a control system and boost converter circuits in an open loop control [2]. Figure 5 shows the LPWM 9-level inverter. Resistance is R. L is the inductance. $\mathrm{C}$ is the capacitor. Ia is the phase current. A 9- Level inverter has eight switches on the positive side of the DC sources while four parts of the DC source on the inverter are constructed with 

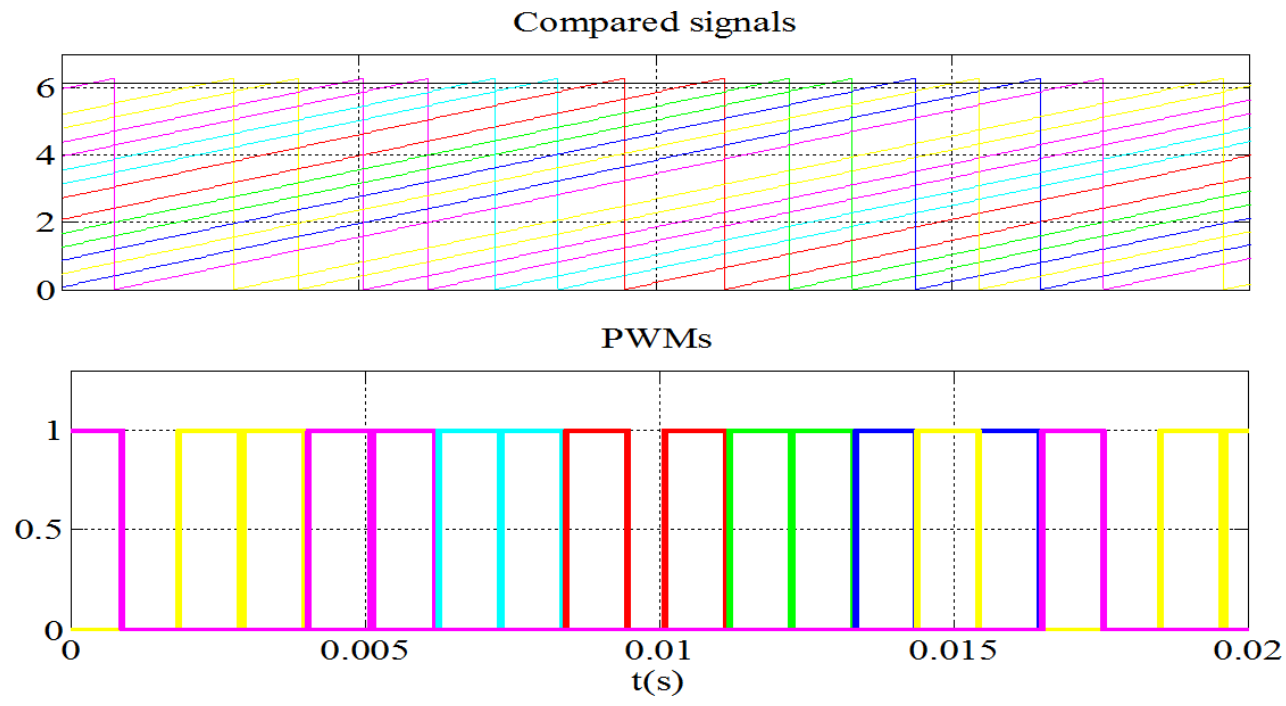

Figure 2. Created PWMs for nine-level inverter with compares signals.

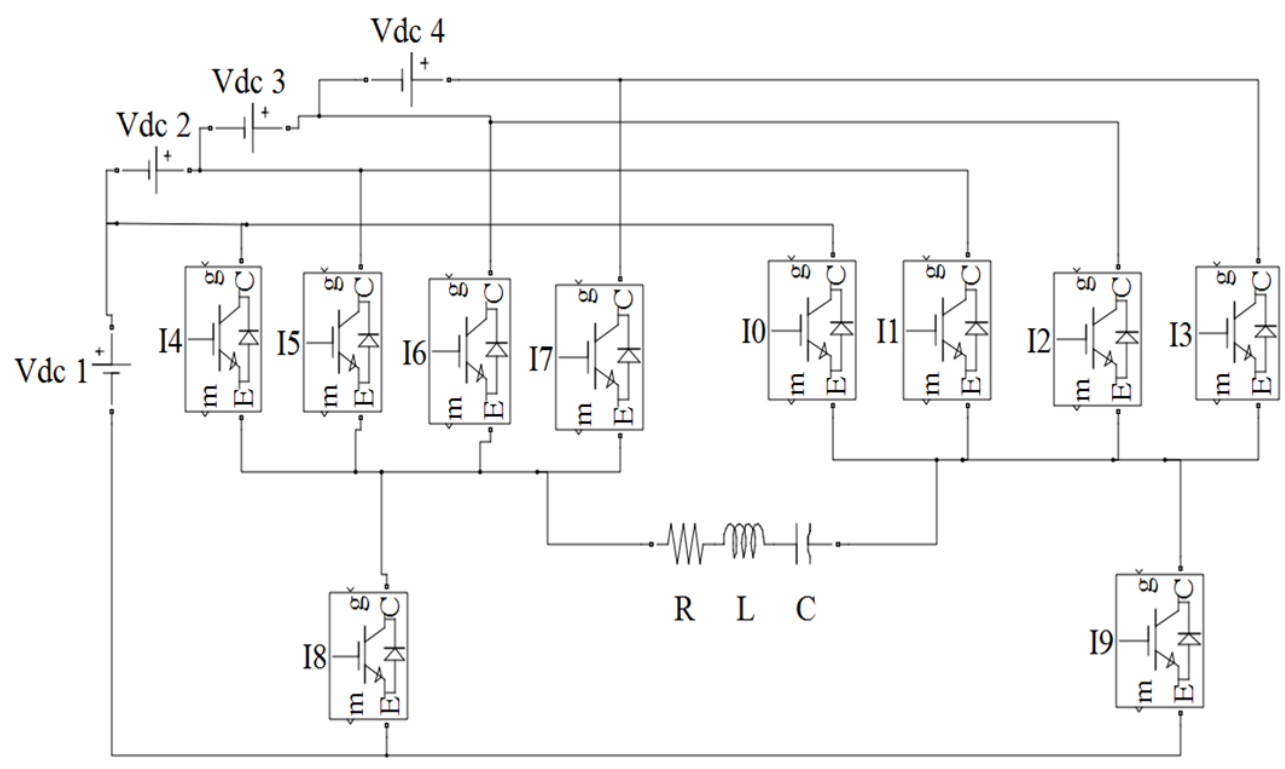

FiguRE 3. Nine-level inverter.

a voltage divider circuit for the nine-level boost inverter. The switch count on the downside of the source continues to be fixed although the switches of the upper side of the source rise to eight. The modulation method is used in Figure 3 so that switches can be operated according to the proposed topology. Table 1 demonstrates the switch operating positions with the modulation technique. According to this operation positions, the nine-level inverter runs at MATLAB SIMULINK in order to form the alternating voltage with vertical divided electrical angles. Therefore, the inverter uses sixteen steps in order to create an alternating voltage as nine-levels.

The mathematical equations for the DC-DC converter are given in (1)-(6). When $\mathrm{S}$ is $\mathrm{ON}$, equations of boost converter circuit are:

$$
\begin{gathered}
V_{g}=V_{L}, \\
I_{\text {max }}-I_{\text {min }}=\frac{V_{g}}{L} D T .
\end{gathered}
$$

When $\mathrm{S}$ is $\mathrm{OFF}$, equations of boost converter circuit are:

$$
\begin{gathered}
V_{g}=V_{L}+V_{c} \\
I_{\min }-I_{\max }=\frac{V_{g}-V_{c}}{L}(1-D) T \\
\frac{V_{g}-V_{c}}{L}(1-D) T=-\frac{V_{g}}{L} D T \\
V_{c}=\frac{V_{g}}{1-D}
\end{gathered}
$$

In the second level voltage, two pieces of voltage for the positive period and two pieces of voltage for the negative period of the voltage occur at the determined angles. For $22.5^{\circ}-45^{\circ} ; 157.5^{\circ}-180^{\circ} ; 202.5^{\circ}-225^{\circ}$; $337.5^{\circ}-360^{\circ}$, a $1 / 4$ of the converter output voltage is employed in S-2 and S-8 for the second level forming on loads. The 2-level for boosted alternating voltage 


\begin{tabular}{cccccccccccc}
\hline & I9 & I8 & I7 & I6 & I5 & I4 & I3 & I2 & I1 & I0 & S \\
\hline S-1 & 0 & 0 & 0 & 0 & 0 & 0 & 0 & 0 & 0 & 0 & 1 \\
S-2 & 1 & 0 & 0 & 0 & 0 & 1 & 0 & 0 & 0 & 0 & 1 \\
S-3 & 1 & 0 & 0 & 0 & 1 & 0 & 0 & 0 & 0 & 0 & 1 \\
S-4 & 1 & 0 & 0 & 1 & 0 & 0 & 0 & 0 & 0 & 0 & 1 \\
S-5 & 1 & 0 & 1 & 0 & 0 & 0 & 0 & 0 & 0 & 0 & 1 \\
S-6 & 1 & 0 & 0 & 1 & 0 & 0 & 0 & 0 & 0 & 0 & 1 \\
S-7 & 1 & 0 & 0 & 0 & 1 & 0 & 0 & 0 & 0 & 0 & 1 \\
S-8 & 1 & 0 & 0 & 0 & 0 & 1 & 0 & 0 & 0 & 0 & 1 \\
S-9 & 0 & 0 & 0 & 0 & 0 & 0 & 0 & 0 & 0 & 0 & 1 \\
$\mathrm{~S}-10$ & 1 & 1 & 0 & 0 & 0 & 0 & 0 & 0 & 1 & 0 & 1 \\
$\mathrm{~S}-11$ & 0 & 1 & 0 & 0 & 0 & 0 & 0 & 1 & 0 & 0 & 1 \\
$\mathrm{~S}-12$ & 0 & 1 & 0 & 0 & 0 & 0 & 1 & 0 & 0 & 0 & 1 \\
$\mathrm{~S}-13$ & 0 & 1 & 0 & 0 & 0 & 1 & 0 & 0 & 0 & 0 & 1 \\
$\mathrm{~S}-14$ & 0 & 1 & 0 & 0 & 0 & 0 & 1 & 0 & 0 & 0 & 1 \\
$\mathrm{~S}-15$ & 0 & 1 & 0 & 0 & 0 & 0 & 0 & 1 & 0 & 0 & 1 \\
$\mathrm{~S}-16$ & 1 & 1 & 0 & 0 & 0 & 0 & 0 & 0 & 1 & 0 & 1 \\
\hline
\end{tabular}

TABLE 1. Switches operating according to steps. Sswitch of converter

created on $R, L$ and $C$ loads is computed from

$$
\frac{2 \mathrm{~d}\left(\frac{V_{g}}{1-D} \frac{1}{4}\right)}{7 \mathrm{~d} t}=R \frac{\mathrm{d} i_{1}}{\mathrm{~d} t}+\frac{i_{1}}{C}+L \frac{\mathrm{d}^{2} i_{1}}{\mathrm{~d} t^{2}}
$$

For $45^{\circ}-67.5^{\circ} ; 135^{\circ}-157.5^{\circ} ; 225^{\circ}-247.5^{\circ} ; 315^{\circ}-337.5^{\circ}$, $2 / 4$ of the converter output voltage is employed in S-3 and S-7 for forming a 3-level. The 3-level for the voltage on $R, L$ and $C$ loads is computed from

$$
\frac{4 \mathrm{~d}\left(\frac{V_{g}}{1-D} \frac{1}{4}\right)}{7 \mathrm{~d} t}=R \frac{\mathrm{d} i_{2}}{\mathrm{~d} t}+\frac{i_{2}}{C}+L \frac{\mathrm{d}^{2} i_{2}}{\mathrm{~d} t^{2}} .
$$

For $67.5^{\circ}-90^{\circ} ; 117.5^{\circ}-135^{\circ} ; 247.5^{\circ}-269.5^{\circ} ; 292.5^{\circ}-315^{\circ}$, $3 / 4$ of the converter output voltage is activated for S-4 and S-6 for creating 4-level. The 4-level for the boosted alternating voltage on $R, L$ and $C$ loads is computed from

$$
\frac{6 \mathrm{~d}\left(\frac{V_{g}}{1-D} \frac{1}{4}\right)}{7 \mathrm{~d} t}=R \frac{\mathrm{d} i_{3}}{\mathrm{~d} t}+\frac{i_{3}}{C}+L \frac{\mathrm{d}^{2} i_{3}}{\mathrm{~d} t^{2}} .
$$

For $90^{\circ}-117.5^{\circ} ; 269.5^{\circ}-292.5^{\circ}, 4 / 4$ of the converter output voltage is activated, The 4-level for the boosted alternating voltage on $R, L$ and $C$ loads is computed from

$$
\frac{4 \mathrm{~d}\left(\frac{V_{g}}{1-D} \frac{1}{4}\right)}{7 \mathrm{~d} t}=R \frac{\mathrm{d} i_{4}}{\mathrm{~d} t}+\frac{i_{4}}{C}+L \frac{\mathrm{d}^{2} i_{4}}{\mathrm{~d} t^{2}} .
$$

The total boosted voltage is derived from (8)-10. The equation for the total alternating voltage is

$$
\begin{aligned}
& \frac{16 \mathrm{~d}\left(\frac{V_{g}}{1-D} \frac{1}{4}\right)}{7 \mathrm{~d} t}=R \frac{\mathrm{d}\left(i_{1}+i_{2}+i_{3}+i_{4}\right)}{\mathrm{d} t} \\
& +\frac{i_{1}+i_{2}+i_{3}+i_{4}}{C}+L \frac{\mathrm{d}^{2}\left(i_{1}+i_{2}+i_{3}+i_{4}\right)}{\mathrm{d} t^{2}}
\end{aligned}
$$

Five parts of the DC source are employed in S- 5 for forming the 5 -level on loads. The 5 -level is computed from

$$
i=i_{1}+i_{2}+i_{3}+i_{4}
$$

Rewriting the total increasing alternating voltage equation with the total current value we get

$$
\frac{16 \mathrm{~d}\left(\frac{V_{g}}{1-D} \frac{1}{4}\right)}{7 \mathrm{~d} t}=R \frac{\mathrm{d} i}{\mathrm{~d} t}+\frac{i}{C}+L \frac{\mathrm{d}^{2} i}{\mathrm{~d} t^{2}} .
$$

\subsection{Controllers}

The fuzzy logic controller was widely used to control electronic circuits for getting better results in some studies [13, 20. In the paper, the applied mathematical model of the system is created and described as a fuzzy logic controlling a new high multilevel inverter with an adapting boost converter. The fuzzy logic uses the equations of the first and second-degree differential equations, based on the determined electrical differences. This is the first time in the literature to establish an equation used for the fuzzy logic controller. Membership functions of fuzzy logic controller are based on the load current of the inverter designed with three triangles. Some logical conditions of the fuzzy logic controller have to be explained to design a fuzzy logic controller. du is derived from the input values of the control error $e$ and the change of the control error de. The value of $e$ is derived from the reference signal $r_{(n)}$ and the output signal $y_{(n)}$ that is the load current of the inverter. The equation of the control error is

$$
e_{(n)}=r_{(n)}-y_{(n)}
$$

The change of the control error is the difference between two control errors in a succession. The control error of the change is described by

$$
\mathrm{d} e=e_{(n)}-e_{(n-1)} .
$$

Because the high multilevel inverter is a 9-level, the values of the control error $e$ and change of the control error de is divided with $22.5^{\circ}$ of the electrical angle. Then, two equations can be formed:

$$
\left\{\begin{array}{r}
e_{1}=e_{9}=\frac{i_{\mathrm{r}}}{8}-\frac{2}{8}\left(R \frac{\mathrm{d} i_{\mathrm{o}}}{\mathrm{d} t}+\frac{i_{\mathrm{o}}}{C}+L \frac{\mathrm{d}^{2} i_{\mathrm{o}}}{\mathrm{d} t^{2}}\right) \\
\frac{22.5^{\circ}-45^{\circ} ; 157.5^{\circ}-180^{\circ}}{202.5^{\circ}-225^{\circ} ; 337.5^{\circ}-360^{\circ}} \\
e_{2}=e_{8}=\frac{i_{\mathrm{r}}}{8}-\frac{2}{8}\left(R \frac{\mathrm{d} i_{\mathrm{o}}}{\mathrm{d} t}+\frac{i_{\mathrm{o}}}{C}+L \frac{\mathrm{d}^{2} i_{\mathrm{o}}}{\mathrm{d} t^{2}}\right) \\
\frac{45^{\circ}-67.5^{\circ} ; 135^{\circ}-157.5^{\circ}}{225^{\circ}-247.5^{\circ} ; 315^{\circ}-337.5^{\circ}} \\
e_{3}=e_{7}=\frac{i_{\mathrm{r}}-\frac{2}{8}\left(R \frac{\mathrm{d} i_{\mathrm{o}}}{\mathrm{d} t}+\frac{i_{\mathrm{o}}}{C}+L \frac{\mathrm{d}^{2} i_{\mathrm{o}}}{\mathrm{d} t^{2}}\right)}{247.5^{\circ}-269.5^{\circ} ; 292.5^{\circ}-315^{\circ}} \\
e_{4}=e_{6}=\frac{i_{\mathrm{r}}-\frac{2}{8}\left(R \frac{\mathrm{d} i_{\mathrm{o}}}{\mathrm{d} t}+\frac{i_{\mathrm{o}}}{C}+L \frac{\mathrm{d}^{2} i_{\mathrm{o}}}{\mathrm{d} t^{2}}\right)}{90^{\circ}-117.5^{\circ}} \\
269.5^{\circ}-292.5^{\circ}
\end{array}\right.
$$


and

$$
\left\{\begin{array}{r}
\mathrm{d} e_{1}=e_{1}-e_{10}, \mathrm{~d} e_{9}=e_{9}-e_{90}, \\
\frac{22.5^{\circ}-45^{\circ} ; 157.5^{\circ}-180^{\circ}}{202.5^{\circ}-225^{\circ} ; 337.5^{\circ}-360^{\circ}} \\
\mathrm{d} e_{2}=e_{2}-e_{1}, \mathrm{~d} e_{8}=e_{9}-e_{8}, \\
\frac{45^{\circ}-67.5^{\circ} ; 135^{\circ}-157.5^{\circ}}{225^{\circ}-247.5^{\circ} ; 315^{\circ}-337.5^{\circ}} \\
\mathrm{d} e_{3}=e_{3}-e_{2}, \mathrm{~d} e_{7}=e_{8}-e_{7}, \\
\frac{67.5^{\circ}-90^{\circ} ; 117.5^{\circ}-135^{\circ} ; 247.5^{\circ}}{247.5^{\circ}-269.5^{\circ} ; 292.5^{\circ}-315^{\circ}} \\
\mathrm{d} e_{4}=e_{4}-e_{3}, \mathrm{~d} e_{6}=e_{7}-e_{6}, \\
\frac{90^{\circ}-117.5^{\circ}}{269.5^{\circ}-292.5^{\circ}}
\end{array}\right.
$$

where $i_{\mathrm{r}}$ is the reference current; $i_{\mathrm{O}}$ is the output current.

If the number of iterations for each level is considered to be three, the error equations are as follows:

$$
\left\{\begin{aligned}
& e_{11}=e_{91}=\frac{i_{\mathrm{r}}}{24}-\frac{2}{24}\left(R \frac{\mathrm{d} i_{o}}{\mathrm{~d} t}+\frac{i_{o}}{C}+L \frac{\mathrm{d}^{2} i_{o}}{\mathrm{~d} t^{2}}\right), \\
& e_{12}=e_{92}= \frac{i_{\mathrm{r}}}{24}-\frac{2}{24}\left(R \frac{\mathrm{d} i_{o}}{\mathrm{~d} t}+\frac{i_{o}}{C}+L \frac{\mathrm{d}^{2} i_{o}}{\mathrm{~d} t^{2}}\right), \\
& e_{13}=e_{93}= \frac{i_{\mathrm{r}}}{24}-\frac{2}{24}\left(R \frac{\mathrm{d} i_{o}}{\mathrm{~d} t}+\frac{i_{o}}{C}+L \frac{\mathrm{d}^{2} i_{o}}{\mathrm{~d} t^{2}}\right), \\
& \frac{22.5^{\circ}-45^{\circ} ; 157.5^{\circ}-180^{\circ}}{202.5^{\circ}-225^{\circ} ; 337.5^{\circ}-360^{\circ}},
\end{aligned}\right.
$$

$$
\left\{\begin{aligned}
e_{21}=e_{81} & =\frac{i_{\mathrm{r}}}{24}-\frac{4}{24}\left(R \frac{\mathrm{d} i_{o}}{\mathrm{~d} t}+\frac{i_{o}}{C}+L \frac{\mathrm{d}^{2} i_{o}}{\mathrm{~d} t^{2}}\right), \\
e_{22}=e_{82}= & \frac{i_{\mathrm{r}}}{24}-\frac{4}{24}\left(R \frac{\mathrm{d} i_{o}}{\mathrm{~d} t}+\frac{i_{o}}{C}+L \frac{\mathrm{d}^{2} i_{o}}{\mathrm{~d} t^{2}}\right), \\
e_{23}=e_{83}= & \frac{i_{\mathrm{r}}}{24}-\frac{4}{24}\left(R \frac{\mathrm{d} i_{o}}{\mathrm{~d} t}+\frac{i_{o}}{C}+L \frac{\mathrm{d}^{2} i_{o}}{\mathrm{~d} t^{2}}\right), \\
& \frac{45^{\circ}-67.5^{\circ} ; 135^{\circ}-157.5^{\circ}}{225^{\circ}-247.5^{\circ} ; 315^{\circ}-337.5^{\circ}},
\end{aligned}\right.
$$

$$
\left\{\begin{aligned}
e_{31}=e_{71}= & \frac{i_{\mathrm{r}}}{24}-\frac{6}{24}\left(R \frac{\mathrm{d} i_{o}}{\mathrm{~d} t}+\frac{i_{o}}{C}+L \frac{\mathrm{d}^{2} i_{o}}{\mathrm{~d} t^{2}}\right), \\
e_{32}=e_{72}= & \frac{i_{\mathrm{r}}}{24}-\frac{6}{24}\left(R \frac{\mathrm{d} i_{o}}{\mathrm{~d} t}+\frac{i_{o}}{C}+L \frac{\mathrm{d}^{2} i_{o}}{\mathrm{~d} t^{2}}\right), \\
e_{33}=e_{73}= & \frac{i_{\mathrm{r}}}{24}-\frac{6}{24}\left(R \frac{\mathrm{d} i_{o}}{\mathrm{~d} t}+\frac{i_{o}}{C}+L \frac{\mathrm{d}^{2} i_{o}}{\mathrm{~d} t^{2}}\right), \\
& \frac{67.5^{\circ}-90^{\circ} ; 117.5^{\circ}-135^{\circ} ; 247.5^{\circ}}{247.5^{\circ}-269.5^{\circ} ; 292.5^{\circ}-315^{\circ}},
\end{aligned}\right.
$$

$$
\left\{\begin{aligned}
& e_{41}=e_{61}= \frac{i_{\mathrm{r}}}{24}-\frac{8}{24}\left(R \frac{\mathrm{d} i_{o}}{\mathrm{~d} t}+\frac{i_{o}}{C}+L \frac{\mathrm{d}^{2} i_{o}}{\mathrm{~d} t^{2}}\right), \\
& e_{42}=e_{62}= \frac{i_{\mathrm{r}}}{24}-\frac{8}{24}\left(R \frac{\mathrm{d} i_{o}}{\mathrm{~d} t}+\frac{i_{o}}{C}+L \frac{\mathrm{d}^{2} i_{o}}{\mathrm{~d} t^{2}}\right), \\
& e_{43}=e_{63}=\frac{i_{\mathrm{r}}}{24}-\frac{8}{24}\left(R \frac{\mathrm{d} i_{o}}{\mathrm{~d} t}+\frac{i_{o}}{C}+L \frac{\mathrm{d}^{2} i_{o}}{\mathrm{~d} t^{2}}\right), \\
& \frac{90^{\circ}-117.5^{\circ}}{269.5^{\circ}-292.5^{\circ}},
\end{aligned}\right.
$$

According to the sampling number three, the change

\begin{tabular}{cccc}
\hline$e$ & \multicolumn{3}{c}{$\mathrm{d} e$} \\
\cline { 2 - 4 } & $\mathrm{Lo}$ & $\mathrm{Av}$ & $\mathrm{Ha}$ \\
\hline $\mathrm{Ha}$ & $\mathrm{Av}$ & $\mathrm{Ha}$ & $\mathrm{Ha}$ \\
$\mathrm{Av}$ & $\mathrm{Lo}$ & $\mathrm{Av}$ & $\mathrm{Ha}$ \\
$\mathrm{Lo}$ & $\mathrm{Lo}$ & $\mathrm{Lr}$ & $\mathrm{Av}$ \\
\hline
\end{tabular}

TABle 2. Some rules for interaction membership according to three membership.

\begin{tabular}{cccccc}
\hline \multirow{2}{*}{$e$} & \multicolumn{5}{c}{$\mathrm{d} e$} \\
\cline { 2 - 6 } & $\mathrm{Lr}$ & $\mathrm{Lo}$ & $\mathrm{Av}$ & $\mathrm{Ha}$ & $\mathrm{Hr}$ \\
\hline $\mathrm{Hr}$ & $\mathrm{Av}$ & $\mathrm{Ha}$ & $\mathrm{Ha}$ & $\mathrm{Hr}$ & $\mathrm{Hr}$ \\
$\mathrm{Ha}$ & $\mathrm{Lo}$ & $\mathrm{Av}$ & $\mathrm{Ha}$ & $\mathrm{Ha}$ & $\mathrm{Hr}$ \\
$\mathrm{Av}$ & $\mathrm{Lo}$ & $\mathrm{Lo}$ & $\mathrm{Av}$ & $\mathrm{Ha}$ & $\mathrm{Ha}$ \\
$\mathrm{Lo}$ & $\mathrm{Lr}$ & $\mathrm{Lo}$ & $\mathrm{Lo}$ & $\mathrm{Av}$ & $\mathrm{Ha}$ \\
$\mathrm{Lr}$ & $\mathrm{Lr}$ & $\mathrm{Lr}$ & $\mathrm{Lo}$ & $\mathrm{Lo}$ & $\mathrm{Av}$ \\
\hline
\end{tabular}

TABLE 3. Five section fuzzy rule decision table.

of the error is described in the following equations.

$$
\left\{\begin{array}{r}
\mathrm{d} e_{11}=e_{11}-e_{10}, \mathrm{~d} e_{91}=e_{91}-e_{90}, \\
\mathrm{~d} e_{12}=e_{12}-e_{11}, \mathrm{~d} e_{92}=e_{92}-e_{91}, \\
\mathrm{~d} e_{13}=e_{13}-e_{12}, \mathrm{~d} e_{93}=e_{93}-e_{92}, \\
\frac{22.5^{\circ}-45^{\circ} ; 157.5^{\circ}-180^{\circ}}{202.5^{\circ}-225^{\circ} ; 337.5^{\circ}-360^{\circ}},
\end{array}\right.
$$

$$
\left\{\begin{array}{r}
\mathrm{d} e_{21}=e_{21}-e_{23}, \mathrm{~d} e_{81}=e_{81}-e_{83}, \\
\mathrm{~d} e_{22}=e_{22}-e_{21}, \mathrm{~d} e_{82}=e_{82}-e_{81}, \\
\mathrm{~d} e_{23}=e_{23}-e_{22}, \mathrm{~d} e_{83}=e_{83}-e_{82}, \\
\frac{45^{\circ}-67.5^{\circ} ; 135^{\circ}-157.5^{\circ}}{225^{\circ}-247.5^{\circ} ; 315^{\circ}-337.5^{\circ}},
\end{array}\right.
$$

$$
\left\{\begin{aligned}
& \mathrm{d} e_{31}=e_{31}-e_{33}, \mathrm{~d} e_{71}=e_{71}-e_{73}, \\
& \mathrm{~d} e_{32}=e_{32}-e_{31}, \mathrm{~d} e_{72}=e_{72}-e_{71}, \\
& \mathrm{~d} e_{33}=e_{33}-e_{32}, \mathrm{~d} e_{73}=e_{73}-e_{72}, \\
& \frac{67.5^{\circ}-90^{\circ} ; 117.5^{\circ}-135^{\circ} ; 247.5^{\circ}}{247.5^{\circ}-269.5^{\circ} ; 292.5^{\circ}-315^{\circ}},
\end{aligned}\right.
$$

$$
\left\{\begin{aligned}
& \mathrm{d} e_{41}=e_{41}-e_{43}, \mathrm{~d} e_{61}=e_{61}-e_{63}, \\
& \mathrm{~d} e_{42}=e_{42}-e_{41}, \mathrm{~d} e_{62}=e_{62}-e_{61}, \\
& \mathrm{~d} e_{43}=e_{43}-e_{42}, \mathrm{~d} e_{63}=e_{63}-e_{62}, \\
& \frac{90^{\circ}-117.5^{\circ}}{269.5^{\circ}-292.5^{\circ}},
\end{aligned}\right.
$$

Table 2 demonstrates the output values of $\mathrm{d} u$ for three triangle memberships after the $e$ and de interaction provides the generation of $\mathrm{d} u$. Because memberships of $e$ and de settle on three triangles, nine rules can be described as below.

Table 3 demonstrates the output values of $(\mathrm{d} u)$ for five triangle memberships after the $(e)$ and $(\mathrm{d} e)$ interaction provides the generation of $(\mathrm{d} u)$. Because memberships of $(e)$ and $(\mathrm{d} e)$ settle on three triangles, 25 -rules can be described. 


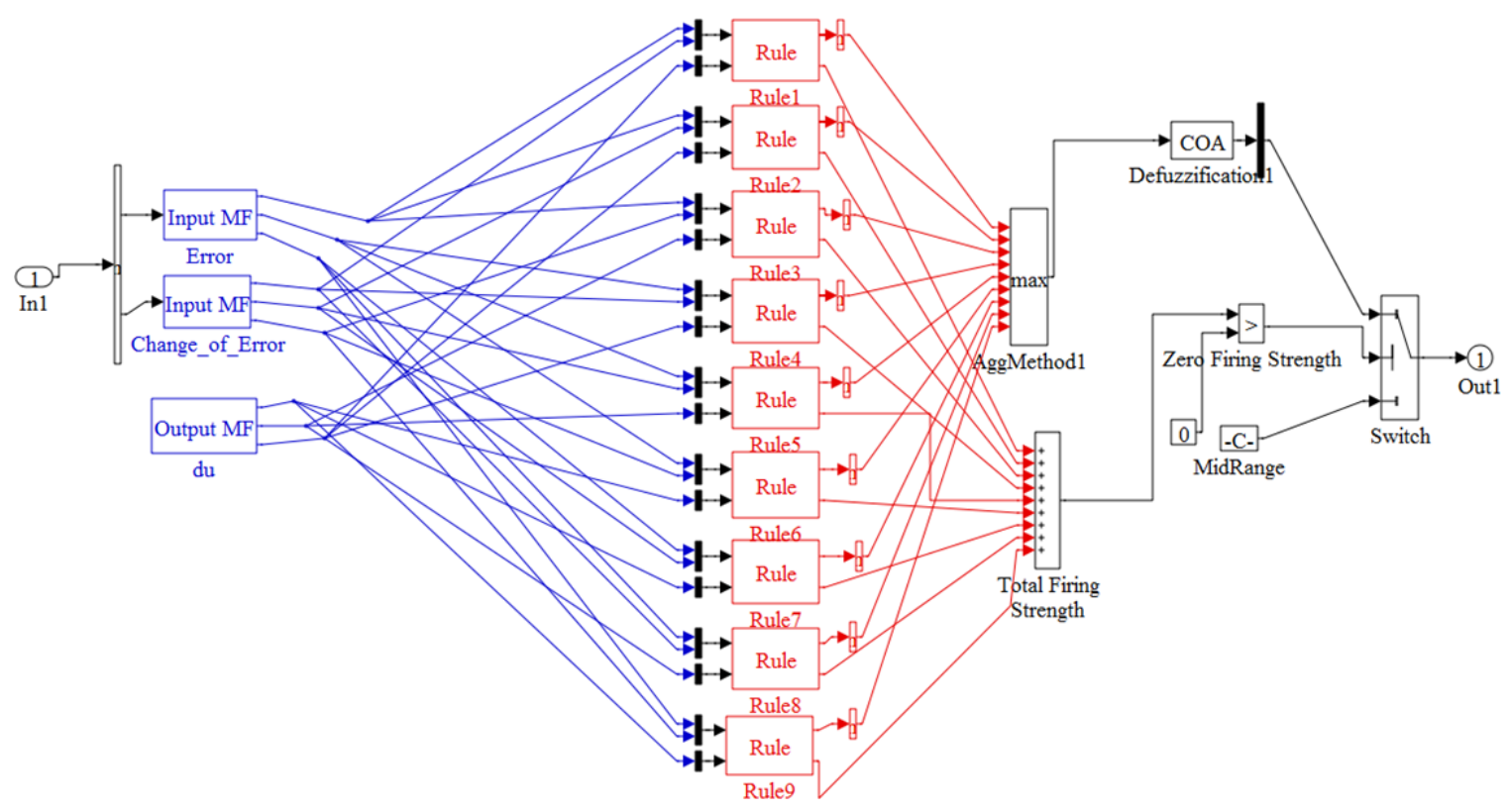

FIGURE 4. Interaction of error and error exchange rules.
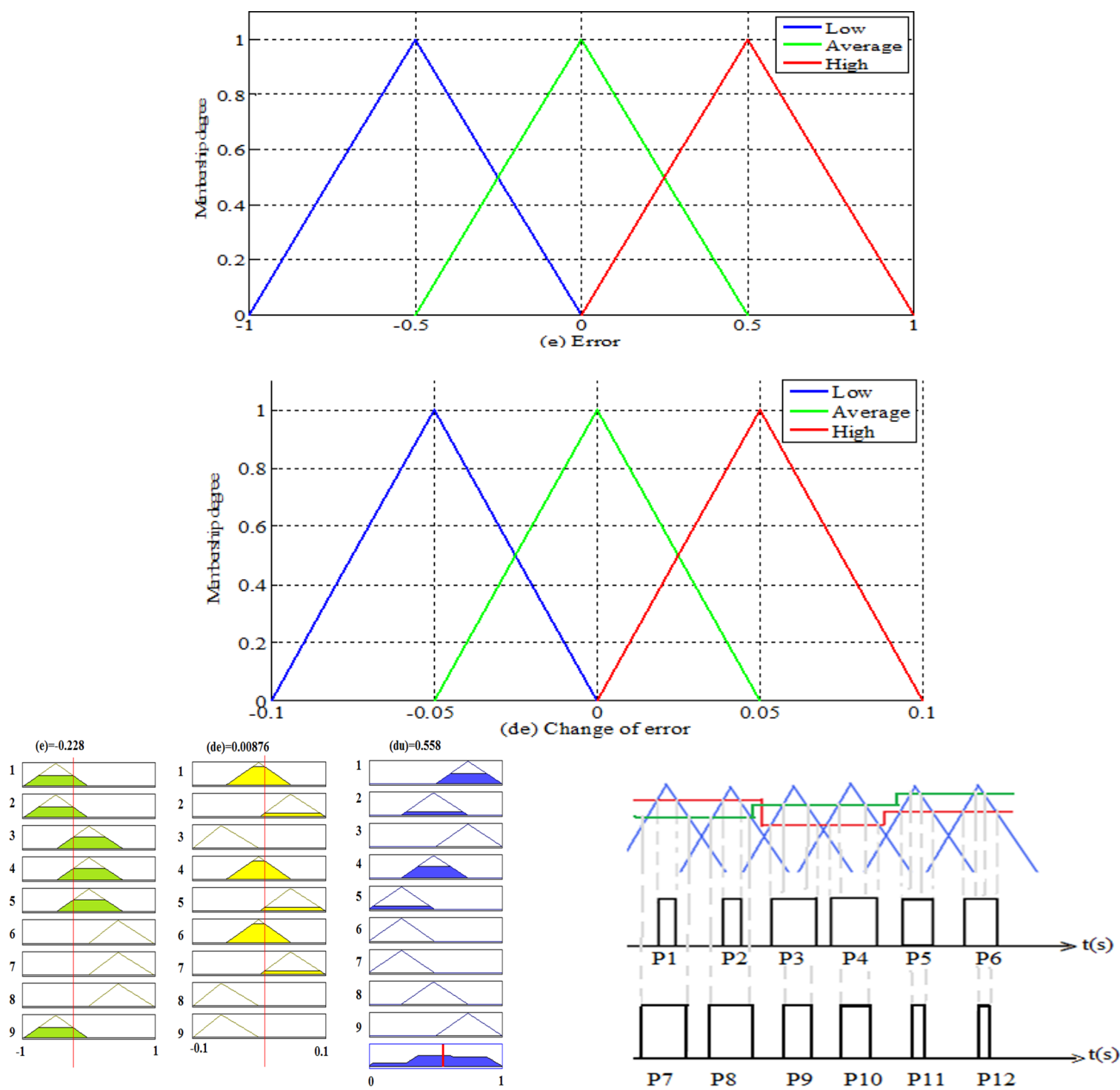

FiguRE 5. (a) Error and error change. (b) The interaction of the error and the change of the error at different points. (c) Change of the PWM according to error and error change. 


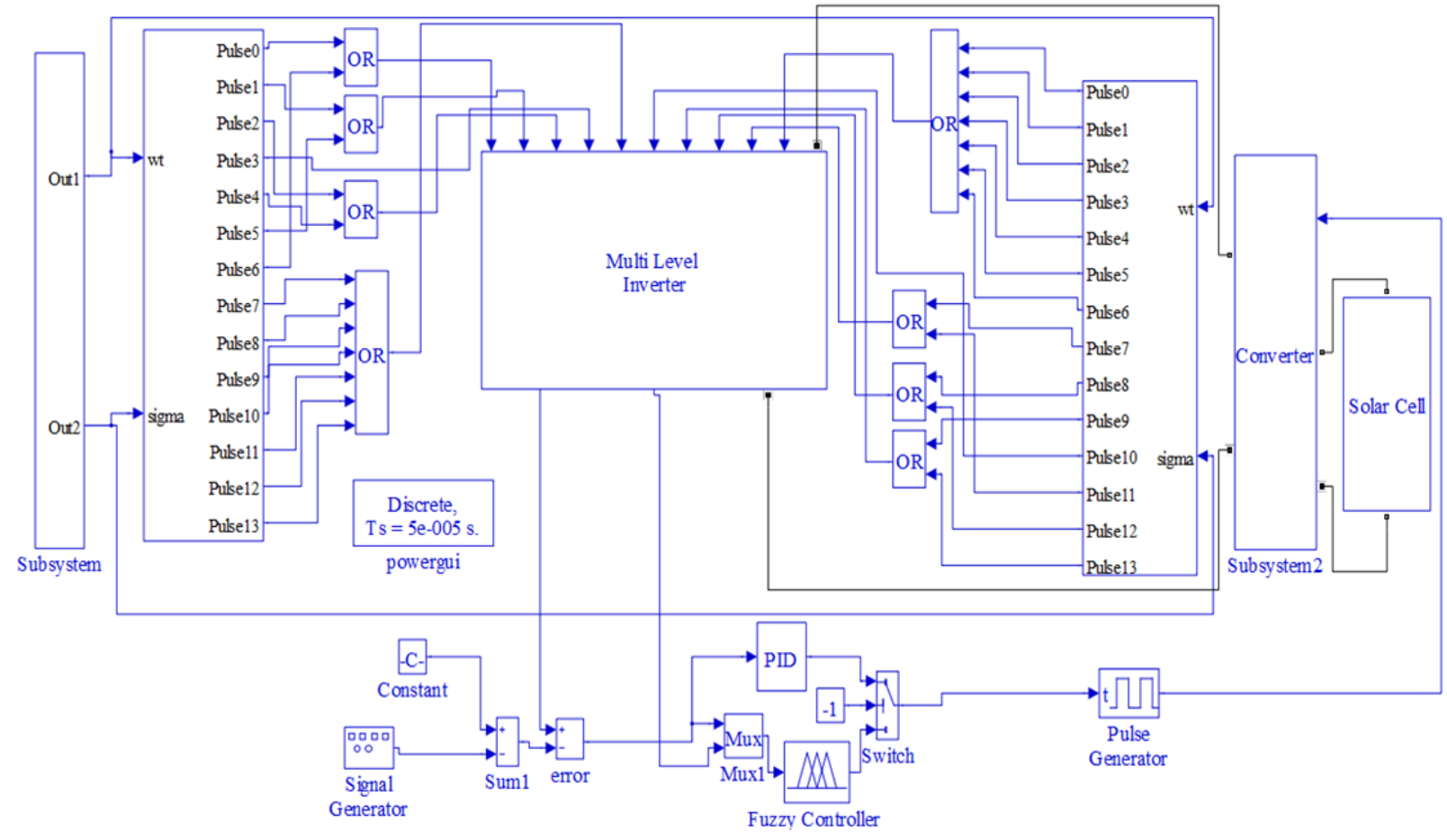

FiguRE 6. Fuzzy logic controlling nine level boost multi-level inverter.
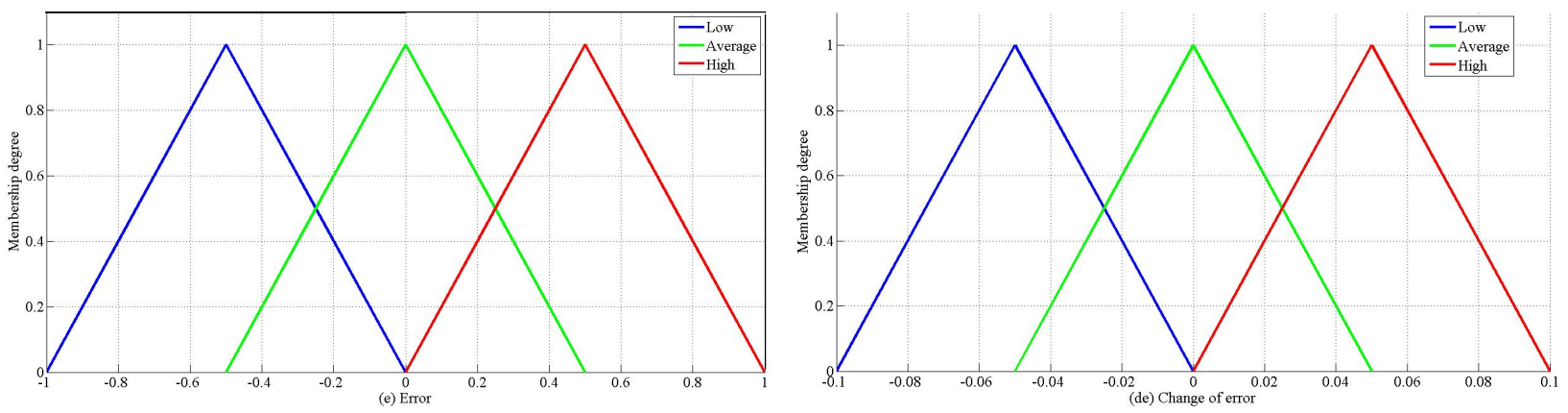

Figure 7. (a) Equal and symmetrical placement of control error. (b) Equal and symmetrical placement of change of control error.

Values $e$ and de produced from the boosting load current of the high multi-level inverter are intersected in order to provide the fuzzyfication. Then, after the decision process is done, du is created in defuzzyfication. Values of du provide a control switch of the converter feeding the multilevel inverter. The interaction of error and error exchange rules are given in Figure 4

If the control error and the control error change are low according to table 2 , then the output value is high in the clarification process in Figure 4 According to the rule table, if the control error is high and the change of control error is low value, the output value goes to the average value in the clarification process. The interaction of the error and the change of the error at different points is shown in Figure $5 \mathrm{p}$ while membership triangles are symmetrical in Figure 5a.

While the error is 0.228 and the change of error is 0.00876 , the output value $\mathrm{d} u$ is 0.558 as shown in Figure $5 \mathrm{~b}$. Hence, an effective correction can be made at the stage of clarification. The operating ratios of the PWMs are determined by the change of the direct signal according to the error and the change of the error as it is shown in Figure 5k. If the error and the change of the error are higher (Hr), the direct signal, which is encountered with the triangular signals, rises and the working ratio of the PWMs decrease as P1, $\mathrm{P} 2, \mathrm{P} 11$ and P12. If the error and the change in the error are lower (Lr), the correct signal intersecting with the triangular signals decreases and the operation rate of the $\mathrm{PWM}$ increases as $\mathrm{P} 3, \mathrm{P} 4, \mathrm{P} 7$ and $\mathrm{P} 8$. If the error and error change is low (Lo), the direct signal is slightly raised and the operating ratios of the PWMs are P5, P6, P9 and P10. The PID control is widely used in order to get a better result from the system. In this study, a comparison between fuzzy logic and traditional PID control methods was made. The Differential expansion of the PID controller is

$$
u(t)=K_{p} e(t)+K_{i} \int e(t) \mathrm{d} t+K_{d} \frac{\mathrm{d} e}{\mathrm{~d} t} .
$$




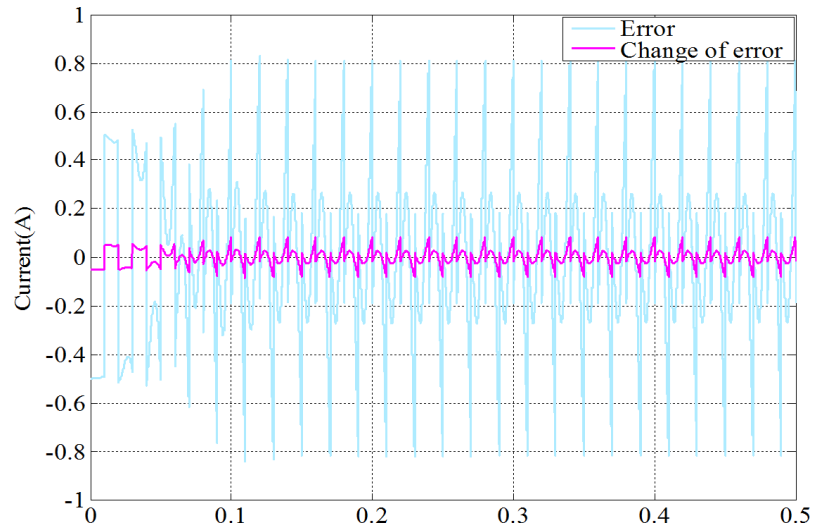

Figure 8 . The input signals applied to the fuzzy logic controller.

The Laplace expansion of the PID controller is

$$
u(t)=K_{p}+\frac{K_{i}}{s}+K_{d}=\frac{K_{p} s^{2}+K_{p} s+K_{i}}{s},
$$

where $K_{p}$ is the value for the proportional gain; $K_{i}$ is the value for the integral gain; $K_{d}$ is the value for the derivation gain.

If $\sqrt{13}$ is to be rearranged with Laplace, we get

$$
i(s)=\frac{16 s}{7 L\left(s^{2}+s \frac{R}{L}+\frac{1}{L C}\right)} V(s) .
$$

If the values of $K_{d}, K_{p}$ and $K_{i}$ in 27) are to be set, we get

$$
i(s)=\frac{16 s K_{p}+K_{i}}{7 L\left(s^{2}+K_{d} s \frac{R}{L}+K_{p} \frac{1}{L C}+K_{i}\right)} V(s) .
$$

\subsection{Simulation Results FOR MUlti-LeVel INVERTER}

A simulation of a nine-level inverter has been performed with the LPWM designed for the inverter controlling after the boost converter is adapted to the high multi-level inverter as it is shown in Figure 6 . The inverter model operates with the fuzzy logic controller when a membership triangle of the controller uses de and $e$, which are produced from load currents.

The proposed circuit structure operates using MATLAB SIMULINK software. The DC-DC converter has inductance $L=0.02 \mathrm{H}$, and $C=1 \mathrm{mF}$ capacitor. The controller determines duty cycle $D$ while the input voltage for the DC-DC converter is $100 \mathrm{~V}$. Values of $R, L$ and $C$ loads in the connecting series are $50 \Omega$, $0.7 \mathrm{H}, 0.8 \mathrm{~F}$ as loads of the inverter. The fuzzy logic controller according to different placement positions of triangles controls the proposed model.

When the control error is between -1 and 1 , the triangle changes symmetrically as shown in Figure 7 a. When the change of the control error is between -0.1 and 0.1 , the triangle changes symmetrically as shown in Figure 7p. The input signals applied to the fuzzy logic controller are given in Figure 8

The Control error and control error change signals in Figure 8 are generated from the load current and

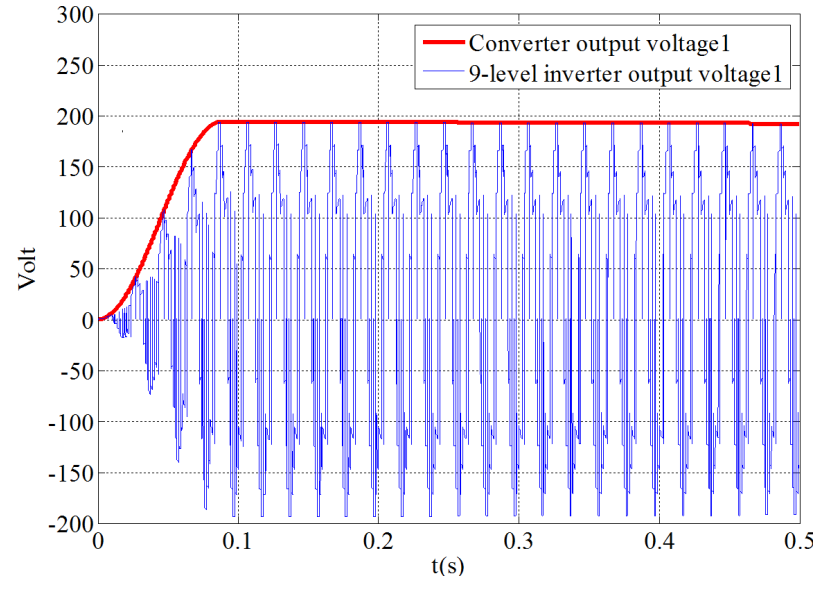

Figure 9. Converter and inverter voltages according to the triangular symmetric positions.

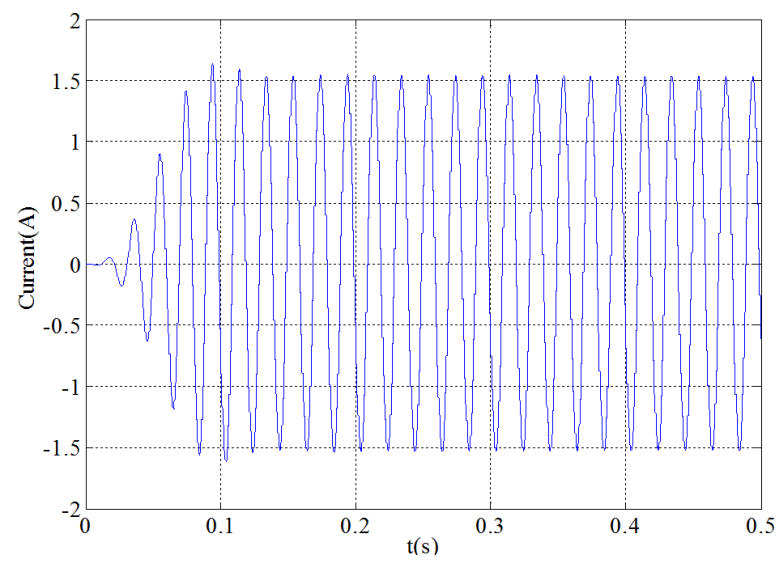

FigURE 10. Inverter load current according to the symmetric triangular positions.

control the system according to the generated rule table. Converter and inverter voltages according to the triangular positions in Figure 7 are as shown in Figure 9.

Current of load forms are shown in Figure 10 while the boosted DC voltage converts to an alternating voltage with the multilevel inverter as shown in Figures 8 and 9. The DC 100 volts applied to the converter reach a balanced 195 volts of the direct voltage at the converter output while the output of the inverter turns into a balanced and symmetrical 195 volts of the alternating voltage.

The load current- 1 is 1.5 amperes symmetrically as it is shown in Figure 10 It is becoming stable at 0.125 seconds. The change of the control error is between -0.1 and 0.1 according to the second set of different triangle positions in Figure 11 a. The average value is between -0.02 and 0.02 while the values of highs and lows are between $-0.1,-0.05$ and $0.05,0.1$ in de in Figure 11].

The average value is between -0.2 and 0.2 while the values of highs and lows are between $-1,-0.5$; $0.5,1$ for $(e)$ in Figure 11 p. The output voltages of the circuit controlled according to these triangular positions are shown in Figure 12 . 

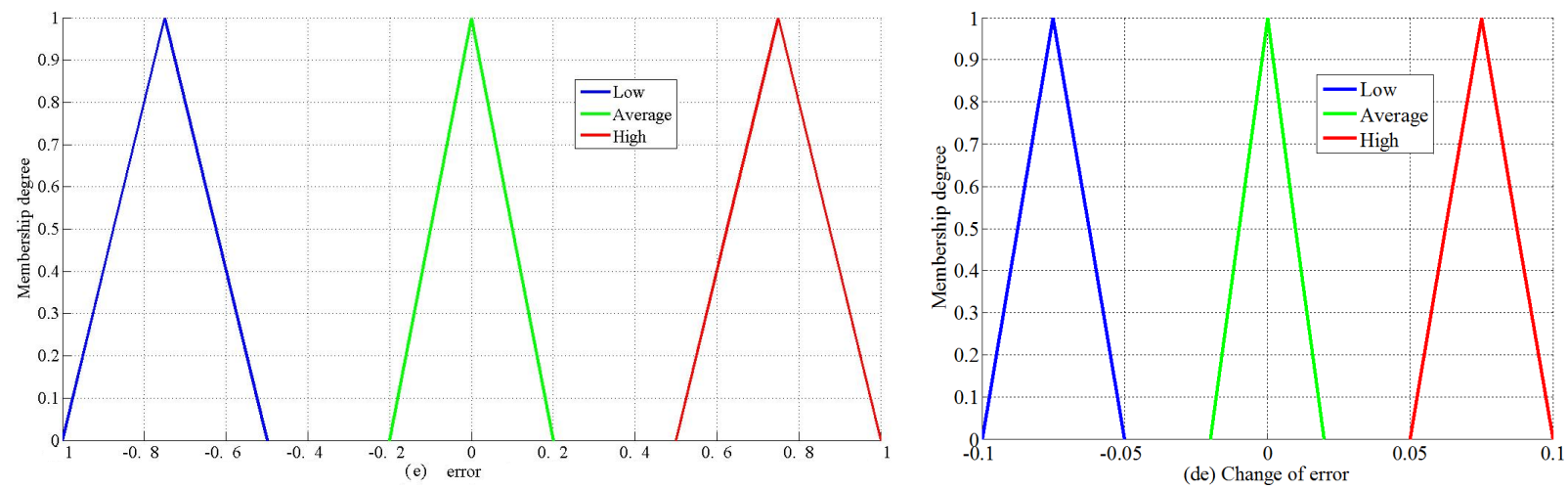

Figure 11. (a) Unequal and symmetrical placement of control error. (b) Unequal and symmetrical placement of change of control error.

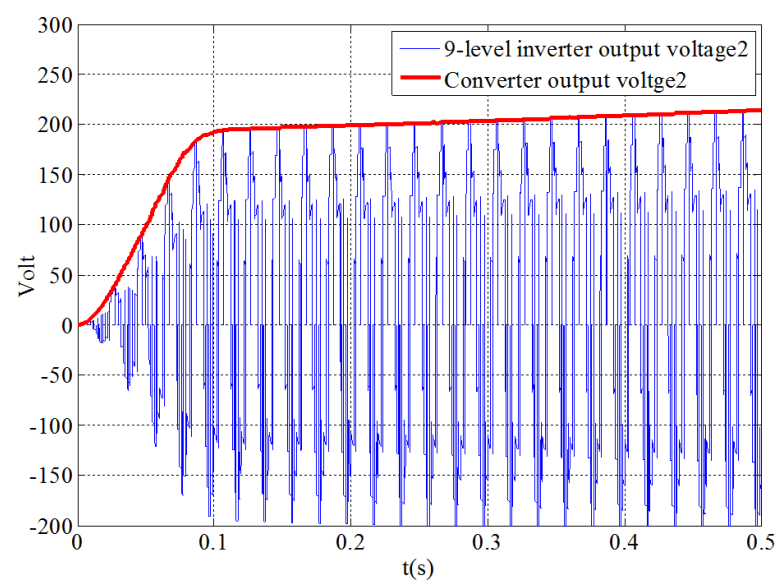

Figure 12. Converter and inverter voltages according to the positions of unequal and symmetric triangular.

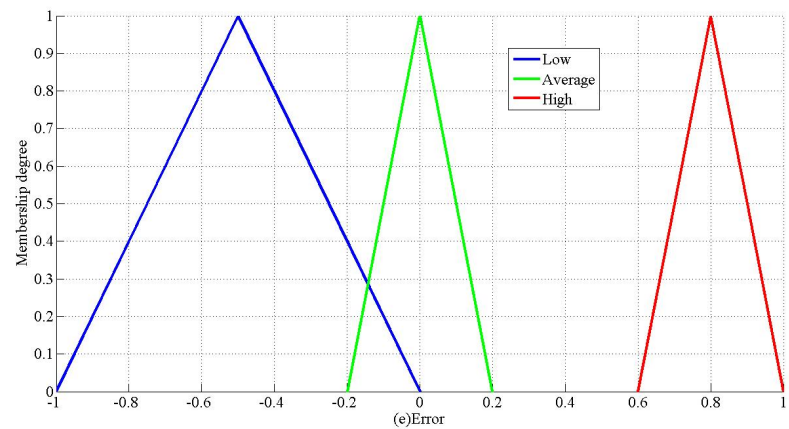

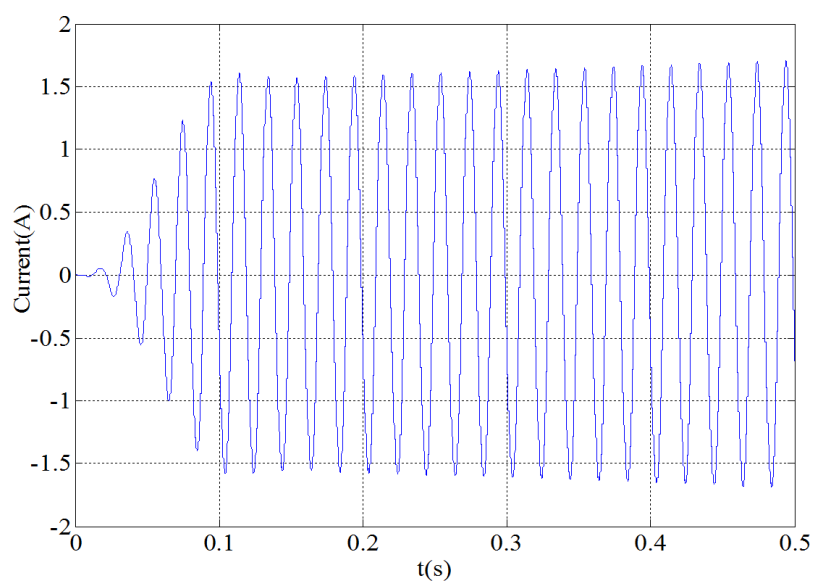

FiguRE 13. Inverter load current according to the unequal and symmetric triangular positions.

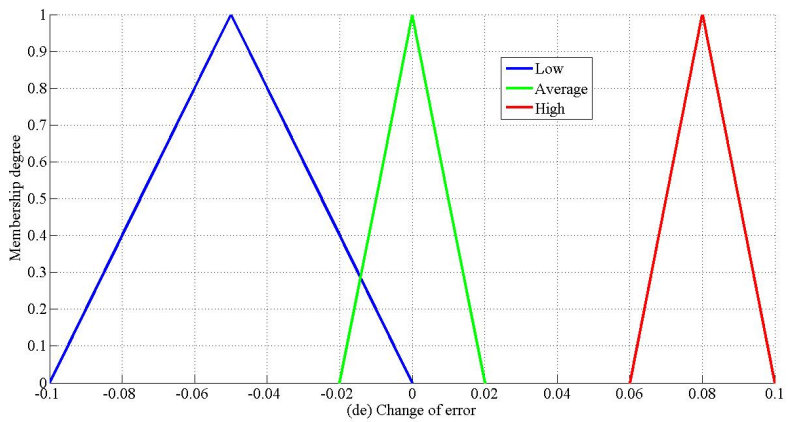

Figure 14. (a) Unequal and unsymmetrical placement of control error. (b) Unequal and unsymmetrical placement of change of control error.

After the DC 100 voltage applied to the converter reaches a balanced 195 volts of direct and alternating voltages at $0.25 \mathrm{~s}$. The converted voltages are increased to 215 volts as balanced direct and alternating voltages at $0.5 \mathrm{~s}$ in Figure 12 Figure 13 shows the load current according to the unequal and symmetric triangular positions.

The load current-2 increases to 1.7 amperes in 0.5 seconds after increasing to 1.55 ampere in 0.25 second. With the change in the position of the triangles created, the increase in the load of voltage and the load current can be provided with increasing time. The change of the control error and the control error are according to the third set of different triangle positions in Figure 14

The control error and the change of control error have an unequal and unsymmetrical placing. Therefore, the low value is between -0.1 and 0.05 ; the value of highs is between $-0.02,0.02$ and the average values are between 0.06 and 0.1 for $\mathrm{de}$ in Figure 14p. The low value is between -1 and 0.5 ; the value of highs is between $-0.2,0.2$ and the average value is $0.6,1$ for $e$ in Figure 14a. The output voltages of the circuit controlled according to these triangular positions are given in Figure 15. 


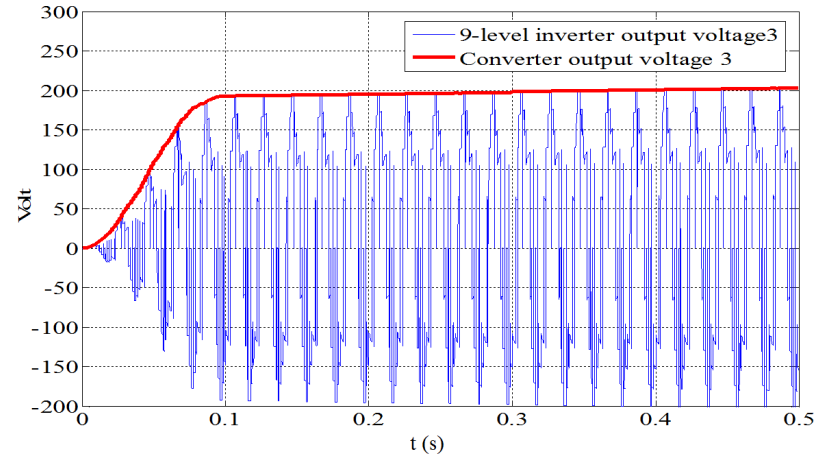

Figure 15. Converter and inverter voltages according to the positions of unequal and asymmetric triangular.

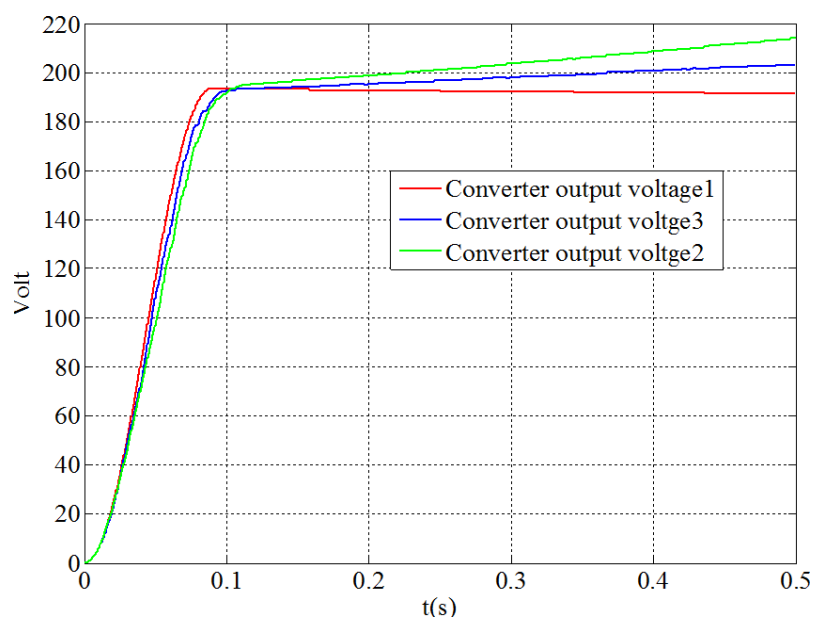

FiguRE 16. three-output voltages of converter.

After the DC 100 voltage applied to the converter reaches a balanced 200 volts of direct and alternating voltages at $0.3 \mathrm{~s}$. the converted voltages are increased to 205 volt as alternating voltage at $0.5 \mathrm{~s}$. Figure 15 . Figure 16 shows the converter output voltages according to the results of the three simulations.

The converter voltage- 1 is balanced and steady at 195 volts while a comparison with other voltages is shown in Figure 16. The converter voltage-3 is 205 volts at $0.5 \mathrm{~s}$ while the converter voltage- 2 is 215 volts at $0.5 \mathrm{~s}$ as shown in Figure 16 . Changes in load of voltage and optimum values could be realized by a nonlinear control method according to the changing positions of the triangles.

The output voltages on the load controlled by the PID and Fuzzy controllers are as shown in Figure 7.

The voltage on the load at the first PID control1 generates oscillations about 206 volts before it stabilizes at 195 volts and 0.018 seconds. In the first fuzzy logic control experiment, the voltage on the load is set at 195 volts and 0.08 second with a non-oscillating manner. In the second fuzzy logic control2 experiment, the voltage on the load is non-oscillating and increasing at 203 volts and 0.5 seconds. In the second PID control test, the voltage on the load is oscillating and increasing at 205 volts and 0.5 seconds. Accord-

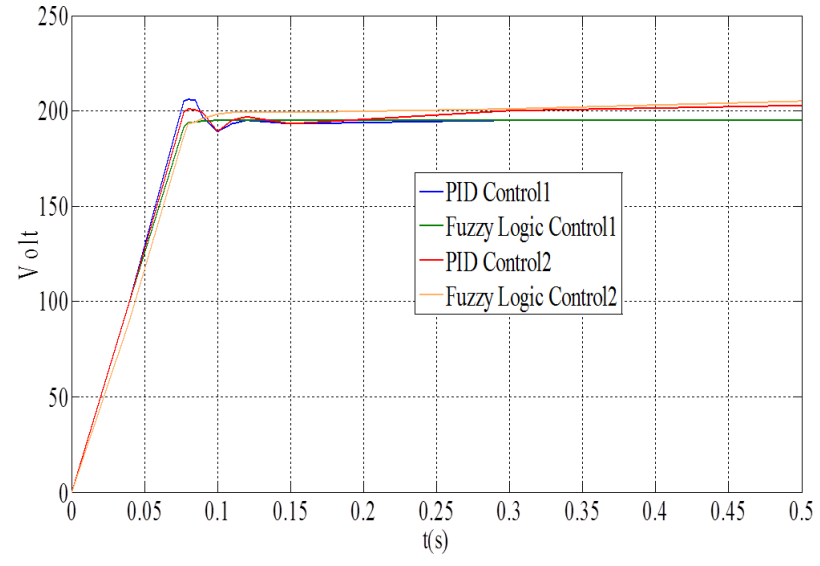

Figure 17. The output voltages on the load controlled by the PID and Fuzzy controllers.

\begin{tabular}{lcc}
\hline & $\begin{array}{c}\text { THD of Fuzzy } \\
\text { Logic Control }\end{array}$ & $\begin{array}{c}\text { THD of PID } \\
\text { Control }\end{array}$ \\
\hline Load current 1 & 1.35 & 2.27 \\
Load current 2 & 1.45 & 2.37 \\
\hline
\end{tabular}

TABLE 4. Harmonic distortion of load currents.

ing to these results, the fuzzy logic control provides more effective and stable control than the conventional PID control. The comparison of the total harmonic distortions can be seen in Table 4

The harmonic distortions of the Fuzzy Logic controlling a nine-level inverter are 1.35 and 1.27. While the harmonic distortions of the PID controlling a nine-level inverter are 2.27 and 2.37. The harmonic distortion of the load currents of the inverter show acceptable values by staying lower than $4 \%$ for each simulation according to results, the proposed inverter topology is more acceptable with the fuzzy logic controller than the conventional PID control.

\section{Conclusion}

An inverter with a boost converter was designed with a new approach in the presented study. The fuzzy logic controller was used in the system so that optimal results could be obtained. The high multi-level inverter performance was measured by a simulation after the model of the full system was created. The DC voltage was increased from low voltage to high voltages with the proposed new inverter topology while a DC-DC converter was operated with a PID and a fuzzy logic controller. The voltage on the load connected to the inverter was tested at various positions of the membership functions of the fuzzy logic controller. The average value was between -0.2 and 0.2 while the values of highs and lows were between $-1,-0.5,0.5,1$ for $(e)$. Then, the input voltage of 100 volts increased to $240 \mathrm{~V}$ at the output of the inverter. When the control error is between -1 and 1 , the triangle changes symmetrically according to the symmetrical settling of triangles at the error and error 
changes. The DC 100 volts applied to the converter reached a balanced 195 volts of the direct voltage at the converter output while the output of the inverter turned into a balanced and symmetrical $195 \mathrm{~V}$ AC. The results of the fuzzy logic controlling the inverter were compared with the results of the PID controlling inverter. According to the PID control, the fuzzy logic stabilized the output voltage faster and without any oscillation. The harmonic distortion in the load current was above $2 \%$ for the PID control, while the harmonic distortion in the load current is above $1 \%$ for the Fuzzy control. Then, the optimal values were obtained over the load, while a nearly $100 \%$ increase in voltage is achieved. The harmonic distortion of the load currents of the inverter shows acceptable values by staying lower than $4 \%$ for each simulation according to results, proposed inverter topology is more acceptable with the fuzzy logic controller for an energy converting and power electronic applications than the conventional PID control.

\section{REFERENCES}

[1] S. P., Gautam, S. Gupta, \& Kumar, L. Reliability improvement of transistor clamped H-bridge-based cascaded multilevel inverter." IET Power Electronics, vol. 10(7): 770-781, 2017.

[2] Can E., Novel High Multilevel Inverters Investigated On Simulation, Electrical Engineering, Pp.1-6, 2016. DOI:10.1007/S00202-016-0396-Z

[3] H., Arpan, S. et al. An Optimized Three-Phase Multilevel Inverter Topology With Separate Level and Phase Sequence Generation Part. IEEE Transactions on Power Electronics, 32.10: 7414-7418,2017.

[4] Harish, D., G. Venkateswara Rao, and D. B. Chowdary. Three Phase Modular Multilevel PV Inverter With Distributed MPPT for Grid-Connected Applications. IJSEAT, 5.1:118-124,2017.

[5] Rao, G. Bhaskar, GV Ram Mohan, and D. B. Chowdary. A New Multilevel Inverter Topology Based on Switched Capacitor for Power Quality Improvement. IJSEAT, 5.1, 161-168,2017.

[6] Bendyk, M. S., Luk, P. C. K., \& Alkhafaji, M. H. Control strategy for a modified cascade multilevel inverter with dual DC source for enhanced drivetrain operation. IEEE Transactions on Industry Applications, 53(5): 4655-4664,2017

[7] Castiglia, V., Miceli, R., Schettino, G., Cimoroni, M. G., Buccella, C., \& Cecati, C. Selective Harmonic Elimination in a 5-Level Single Phase Converter with FPGA Based Controller. In 2018 5th International Symposium on Environment-Friendly Energies and Applications (EFEA) (pp. 1-6).
[8] Bauer, J. Single phase voltage source inverter photovoltaic application. Acta Polytechnica, 50.4 (2010).

[9] Can, E., \& Sayan, H. H. PID and fuzzy controlling three phase asynchronous machine by low level DC source three phase inverter. Tehnički vjesnik, 23(3): 753-760,2016.

[10] Nagle, P., Sharma, C. S., Hirani, M., \& Phulambrikar, S. . Cascade H-Bridge Multilevel Inverter Fed Induction Motor Drive. Development, 5(1):2017.

[11] Dudrik, J., \& Oetter, J. (2007). High-frequency soft-switching dc-dc converters for voltage and current dc power sources. Acta Polytechnica Hungarica, 4(2): 29-46,2007.

[12] Su, G. J. Pulse-Width-Modulation Schemes for an Integrated Traction and Compressor Drive System. 21st Applied Power Electronics Conference and Exposition (APEC'06), vol. 2, March 19-23, pp. 640-645,2006.

[13] Attia, A. F. A. INTELLIGENT CONTROLLER FOR TRACKING A 14-INCH CELESTRON TELESCOPE. Acta Polytechnica, 58(5):271-278, 2018.

[14] Saygin, Ali, Ahmet Aksoz, and Ercan Nurcan Yilmaz.:A different model of WECS connected to smart grid through matrix converter. Smart Grid Congress and Fair (ICSG), 2016 4th International Istanbul. IEEE, 2016

[15] Hussein Sarhan; Rateb Issa. Improving Mechanical Characteristics of Inverter-induction Motor Drive System, in Proceedings of American Journal of Applied Sciences. 3(8): pp. 1961-1966,2006.

[16] Chao, Kuei-Hsiang, and Pi-Yun Chen. An Intelligent Fault Diagnosis Method Based on Extension Theory for DC-AC Converters. International Journal of Fuzzy Systems, 17.1:105-115.,2015.

[17] Logeswaran, T., A. Senthilkumar, and P. Karuppusamy. Adaptive neuro-fuzzy model for grid-connected photovoltaic system. International Journal of Fuzzy Systems, 17.4: 585-594,2015.

[18] Ismail H Altas, Adel M Sharaf"A generalized direct approach for designing fuzzy logic controllers in Matlab/Simulink GUI environment" International Journal of Information Technology and Intelligent Computing, no.4 vol.1: 2007.

[19] Sekhar, V. R., Sridhar, S., \& Bhavani, B. S. The Dynamic Load Model for Medium Voltage Cascaded H-Bridge Multi-Level Inverter fed IM Drive System using Fuzzy Logic Controller.4(2) : 2395-6011, 2018.

[20] Hussain, R., \& Raju, D. B. Fuzzy Logic Controlled Based Z Source Multilevel Inverter Fed Induction Motor For Power Quality Enhancement. Indian J. Sci. Res., 17(2): 149-153,2018.

[21] Hilloowala, R. M., \& Sharaf, A. M. A rule-based fuzzy logic controller for a PWM inverter in a stand alone wind energy conversion scheme. IEEE Transactions on Industry Applications, 32(1): 57-65,1996. 